\title{
Capsule Commentary on Edelman et al., Nurse-Led Behavioral Management of Diabetes and Hypertension in Community Practices: A Randomized Trial
}

\author{
Saul Blecker, MD, MHS ${ }^{1,2}$ and Joseph Ravenell, MD, MS $S^{1,2}$ \\ 'Department of Population Health, New York University School of Medicine, New York, NY, USA; '2Department of Medicine, New York University \\ School of Medicine, New York, NY, USA.
}

J Gen Intern Med 30(5):653

DOI: $10.1007 / \mathrm{s} 11606-015-3207-8$

(c) Society of General Internal Medicine 2015

E delman and colleagues report on a randomized control trial to test the effectiveness of a telephone-based nurse behavioral management intervention for patients with diabetes and hypertension. ${ }^{1}$ Patients who received the intervention showed no improvement in primary endpoints of systolic blood pressure or HbA1c compared to patients in the control group. Additionally, the two groups were similar for all secondary outcomes, including diastolic blood pressure, weight, and physical activity.

The negative findings from this well-designed study are notable, and lead to the question of why the intervention was not effective. The authors suggest a number of important possibilities, including the use of an active control, inclusion of patients at blood pressure goal, and a study that may have been underpowered. The authors propose that setting may play a key role, as they have shown similar interventions to be effective in academic centers and were interested in testing whether such positive results could be extended to a community setting. We believe differences in settings may play a lesser role in the observed lack of effectiveness of a patientlevel intervention conducted by a nurse with extensive experience with the intervention. The study results may point more to a lack of potency of nurse-led telephonic interventions that solely feature behavioral counseling. ${ }^{2}$ The most efficacious nurse-led interventions to control blood pressure to date have included 1) a stepped treatment algorithm to attain desired targets and/or 2) a self-monitoring (i.e., home blood pressure monitoring) component. ${ }^{3,4}$ The intervention under study did not include either of these components, and relied solely on nurse-delivered health education and behavioral counseling.

Nurse-led telephone behavioral management is likely being increasingly used in practice settings for both blood pressure and diabetes management. The current study suggests that counseling-only interventions may not be effective. We believe the growing trend towards nurse-led behavioral management can be valuable, but further research is needed to determine how to best augment behavioral counseling interventions to be most successful in multiple practice settings.

Conflict of Interest: The authors have no conflicts of interest with regard to this article. Dr. Blecker was supported by the Agency for Healthcare Research and Quality grant 1K08 HS23683.

Corresponding Author: Saul Blecker, MD, MHS; Department of Population Health, New York University School of Medicine, New York, NY, USA (e-mail: Saul.Blecker@nyumc.org).

\section{REFERENCES}

1. Edelman D, Dolor RJ, Coffman CJ, Pereira KC, Granger BB, Lindquist BB, Near AM, Harris AM, Bosworth HB. Nurse-Led Behavioral Management of Diabetes and Hypertension in Community Practices: A Randomized Trial. J Gen Intern Med. doi:10.1007/s11606-014-3154-9

2. Bosworth HB, Olsen MK, Grubber JM, et al. Two self-management interventions to improve hypertension control: a randomized trial. Ann Intern Med. 2009; 151(10):687-695.

3. Clark CE, Smith LF, Taylor RS, Campbell JL. Nurse led interventions to improve control of blood pressure in people with hypertension: systematic review and meta-analysis. BMJ. 2010;341:c3995.

4. Clark CE, Smith LF, Taylor RS, Campbell JL. Nurse-led interventions used to improve control of high blood pressure in people with diabetes: a systematic review and meta-analysis. Diabet Med. 2011;28(3):250-261.

Published online February 10, 2015 